\title{
DESIDRATAÇÃO OSMÓTICA DE MANGA SEGUIDA DE SECAGEM CONVENCIONAL: AVALIAÇÃO DAS VARIÁVEIS DE PROCESSO
}

\author{
Osmotic dehydration of mango followed by conventional drying: \\ evaluation of process variables
}

\author{
Manoel Alves de Souza Neto', Geraldo Arraes Maia², Janice Ribeiro Lima ${ }^{3}$, \\ Raimundo Wilane de Figueiredo ${ }^{4}$, Men de Sá Moreira de Souza Filho ${ }^{5}$, Andréa da Silva Lima ${ }^{6}$
}

\begin{abstract}
RESUMO
A manga é uma fruta muito popular dos trópicos, consumida principalmente na forma in natura e com grandes possibilidades de industrialização. A desidratação osmótica seguida de secagem convencional tem se apresentado como uma ferramenta tecnológica importante no desenvolvimento de novos produtos, viabilizando o aproveitamento e valorização da manga. O presente trabalho teve como objetivo avaliar a influência da concentração do xarope osmótico e da pressão do sistema sobre a cinética de desidratação osmótica da manga, assim como sobre o processo de secagem subseqüente. Verificou-se durante todo o processo a influência das variáveis estudadas, notadamente da utilização de vácuo que possibilitou a redução do tempo total de processo.
\end{abstract}

Termos para indexação: Mangifera indica L., vácuo, desidratação osmótica.

\begin{abstract}
Mango is a very popular tropical fruit, consumed mainly in the fresh form, with great possibilities of industrialization. Osmotic dehydration followed by air-drying has been presented as an important technological tool to the development of new products, making possible use the mango to obtain high-value products. The aim of this work was to evaluate the influence of the osmotic syrup concentration and system pressure on the osmotic dehydration of mango, as well as on the subsequent air-drying process. It was observed that the process was influenced by the variables studied, specially by the vacuum application, which reduced the total process time.
\end{abstract}

Index terms: Mangifera indica L., vacuum, osmotic dehydration.

(Recebido para publicação em 22 de setembro de 2004 e aprovado em 27 de junho de 2005)

\section{INTRODUÇÃO}

A manga (Mangifera indica L.) apresenta grandes possibilidades de industrialização, mas ainda não é devidamente explorada. A viabilização do aproveitamento racional da manga, com o desenvolvimento de novos produtos, preservando ao máximo os componentes nutricionais dessa fruta, seria extremamente importante para o Brasil, o qual se apresenta como grande produtor mundial de manga (RIBEIRO \& SABAA-SRUR, 1999).

A desidratação osmótica, ou alternativamente denominada impregnação ou saturação, tem sido considerada uma ferramenta tecnológica importante para se desenvolver novos produtos derivados de frutas, com valor agregado e com propriedades funcionais (TORREGGIANI \& BERTOLO, 2001). A desidratação por osmose consiste na imersão do alimento sólido, inteiro ou em pedaços, em soluções aquosas concentradas de açúcares ou sais, levando a dois fluxos de massa simultâneos: fluxo de água do alimento para a solução devido à diferença na pressão osmótica e transferência simultânea de soluto da solução para o alimento, devido aos gradientes de concentração (TORREGGIANI, 1993). A pressão operacional é um fator importante na cinética de transferência de massa durante a desidratação osmótica de alimentos (SHI \& FITO, 1993). Portanto, tem-se estudado a aplicação de vácuo na desidratação osmótica de várias frutas, podendo esta técnica manifestar algumas características que conduzem à vantagens importantes em sua aplicação industrial (SHI et al., 1995). A desidratação por osmose geralmente não fornece produto com umidade suficientemente baixa para ser considerado estável em prateleira sob temperatura ambiente. Portanto, é usada como uma etapa anterior ao processo de liofilização, secagem a ar quente e microondas (MASTRANGELO et al., 2000).

\footnotetext{
${ }^{1}$ Engenheiro Químico, Mestre, EMBRAPA - Rua Dra. Sara Mesquita, 2270 - Planalto Pici - 60511-110 - Fortaleza, CE.

${ }^{2}$ Engenheiro Agrônomo, Ph.D., Universidade Federal do Ceará

${ }^{3}$ Engenheira de Alimentos, Doutor, EMBRAPA - CE

${ }^{4}$ Engenheiro Agrônomo, Doutor, Departamento de Tecnologia de Alimentos/Centor Ciências Agrárias/Universidade Federal do Ceará - Cx. P. 12168 60356-000 - Fortaleza, CE.

${ }^{5}$ Engenheiro Químico, Mestre, EMBRAPA - CE.

${ }^{6}$ Química Industrial, Mestre, Universidade Federal do Ceará.
} 
A secagem com ar aquecido é um processo antigo utilizado para preservar alimentos, no qual o sólido a ser seco é exposto a uma corrente de ar quente que flui continuamente e assim a umidade é removida. Apesar de garantir a estabilidade do alimento por longos períodos de estocagem, decréscimos na qualidade do produto final pode ser observado tais como: dureza excessiva, degradação da cor, aroma e sabor (RATTI, 2001). A pré-secagem por osmose tem sido utilizada para minimizar os efeitos adversos que geralmente aparecem quando o produto é submetido à secagem a ar quente (DEL VALLE et al., 1998). Esta combinação de métodos de secagem tem sido apontada como alternativa econômica e segura para a conservação de produtos alimentícios, além de possibilitar a obtenção de produtos desidratados de melhor qualidade quando comparado aos produtos desidratados convencionalmente (BRANDÃO et al., 2003). A desidratação osmótica associada a outros fatores de conservação tem produzido alimentos de boa qualidade, de fácil conservação e praticidade. Estes podem ser consumidos diretamente como produtos prontos para o consumo ou como ingredientes para a elaboração de produtos de confeitaria, iogurtes, sorvetes, entre outros (LOPÉZ-MALO, 1994).

O presente trabalho teve como objetivo estudar a influência da concentração do xarope osmótico e da pressão do sistema sobre os fenômenos de transporte de massa durante a desidratação osmótica da manga, assim como sobre o processo de secagem subseqüente.

\section{MATERIAL E MÉTODOS}

No trabalho foram utilizadas mangas da cultivar coité, fornecidas por produtores que exploram a cultura na região de Pindoretama-Ceará, em estádio de maturação ideal para consumo, selecionadas observando-se critérios de uniformidade do grau de maturação e integridade física. Os frutos foram lavados em água clorada (50 ppm/15min), descascados, cortados manualmente em cubos (aproximadamente $3,0 \mathrm{~cm}$ ) e branqueados em vapor saturado fluente $\left(100^{\circ} \mathrm{C} / 2 \mathrm{~min}\right)$. Os cubos de manga foram então pesados e imersos em xarope de sacarose, na proporção fruta:xarope de 1:4, e mantidos sob osmose à temperatura de $65^{\circ} \mathrm{C}$ por 5 horas. Foram avaliadas três diferentes concentrações de xarope: $45^{\circ}, 55^{\circ}$ e $65^{\circ}$ Brix. Os experimentos foram realizados sob pressão atmosférica e com utilização de vácuo $(660 \mathrm{mmHg})$, nas mesmas condições, totalizando 6 tratamentos. A etapa de desidratação osmótica foi realizada em tacho de aço inoxidável, com camisa de aquecimento por resistência elétrica, e sistema de vácuo por bomba d'água. Para a preparação dos xaropes osmóticos, utilizou-se açúcar cristalizado granulado, adquiridos em mercado local. Os conservantes químicos adicionados ao xarope foram: ácido cítrico de grau alimentício (monohidratado), fabricado pela FERMENTA LTDA-SP, para corrigir o $\mathrm{pH}$, e benzoato de sódio de grau alimentício (98\%), fabricado por LIQUID QUÍMICA S.A, para a estabilização do produto final. Os xaropes foram preparados por meio da adição de açúcar à água (até atingir o teor de sólidos solúveis desejado), sob aquecimento. Em seguida, foram adicionados ácido cítrico (até atingir $\mathrm{pH} 3,0)$ e benzoato de sódio $(0,1 \%)$. A quantidade de xarope utilizada no processo deve ser a necessária para se estabelecer a proporção fruta:xarope de 1:4. Segundo Lima et al. (2004), os fluxos de massa que ocorrem durante o processo, levam a uma variação da concentração dos xaropes e à diminuição dos gradientes de concentração entre fruta e xarope ao longo do processo. A utilização de maiores quantidades de xarope minimizam o efeito da diluição do xarope osmótico aumentando a eficiência da desidratação.

Após a avaliação da etapa de osmose, foram selecionados 2 tratamentos para posterior secagem em estufa: um tratamento osmótico sob pressão atmosférica e outro sob vácuo. A secagem complementar foi realizada em estufa de circulação forçada de ar a uma temperatura de $65^{\circ} \mathrm{C}$ até que os frutos atingissem atividade de água menor que 0,75 .

Para avaliação dos tratamentos osmóticos foram retiradas amostras de manga ( 15 cubos por amostra) no início e a cada hora de desidratação osmótica. Durante a secagem foram retiradas amostras a cada duas horas, até a finalização da secagem. Foram realizadas as seguintes determinações: 1- atividade de água (AqualabDecagon Modelo CX-2); 2- umidade (AOAC, 1992); 3teor de sólidos solúveis totais (refratômetro de bancada ABBE); 4- perda de peso do produto (balança digital Denver Instrument Modelo XP-1500). Todas as determinações foram feitas em triplicata. Os valores obtidos nas determinações analíticas durante a desidratação osmótica foram utilizados para calcular os percentuais de perda de água, ganho de sólidos e perda de peso pelo fruto conforme as equações citadas por Sacchetti et al. (2001).

Perda percentual de água (com base na massa inicial do material), definida por:

$$
\mathrm{P}_{\mathrm{A}}(\%)=\underline{(\mathrm{Mo} \times \mathrm{Uo})-(\mathrm{Mt} \times \mathrm{Ut})}
$$

Mo

Ciênc. agrotec., Lavras, v. 29, n. 5, p. 1021-1028, set./out., 2005 
Ganho percentual de sólidos (com base na massa inicial do material):

$$
\mathrm{G}_{\mathrm{S}}(\%)=\frac{(\mathrm{Mt} \times \mathrm{Bt})-(\mathrm{Mo} \times \mathrm{Bo})}{\mathrm{Mo}}
$$

Perda percentual de peso:

$$
\mathrm{P}_{\mathrm{P}}(\%)=\frac{\text { Mo }-\mathrm{Mt}}{\mathrm{Mo}} \times 100
$$

Onde:

$$
\begin{aligned}
& \mathrm{P}_{\mathrm{A}}(\%) \text { - Perda de água, em \% (p/p) } \\
& \mathrm{G}_{\mathrm{S}}(\%) \text { - Ganho de sólidos, em \% (p/p) } \\
& \mathrm{P}_{\mathrm{P}}(\%) \text { - Perda de peso, em \% (p/p) } \\
& \text { Mo - Massa do fruto no tempo } \mathrm{t}=0 \text {, em gramas } \\
& \text { Mt - Massa do fruto tratado no tempo t, em gramas } \\
& \text { Bo } \quad-{ }^{\circ} \text { Brix do fruto no tempo } \mathrm{t}=0 \\
& \text { Bt } \quad-{ }^{\circ} \text { Brix do fruto tratado no tempo } t \\
& \text { Uo - Umidade do fruto no tempo } \mathrm{t}=0 \text {, em } \% \text { base }
\end{aligned}
$$

\section{RESULTADOS E DISCUSSÃO}

As Figuras 1 a 3 mostram dados da perda de água, ganho de sólidos e perda de peso, respectivamente, durante a desidratação osmótica de manga sob pressão atmosférica, para as três soluções osmóticas estudadas.

Nas Figuras 1 e 2, observa-se que as velocidades de perda de água e ganho de sólidos foram maiores na primeira hora da desidratação, tendendo ao equilíbrio no final do período de 5 horas, não sendo observadas alterações significativas dos valores percentuais de perda de água e ganho de sólidos a partir de 4 horas de osmose. Este comportamento está de acordo com o que foi observado por Panagiotou et al. (1999), os quais estudaram a cinética de desidratação osmótica sob pressão atmosférica de diversas frutas, tais como maçã, banana e kiwi.

Observa-se ainda que os aumentos na concentração inicial de sacarose no xarope osmótico promoveram aumentos na taxa de perda de água durante o processo, devido ao aumento na pressão osmótica no exterior da fruta, conforme foi relatado por Mizrahi et al. (2001).
Verifica-se que o uso de xaropes mais concentrados (Figuras 1 e 2), apesar de ter intensificado a perda de água, apresentou o inconveniente aumento do ganho de sólidos. Segundo Torreggiani (1993), na desidratação osmótica a perda de água é acompanhada por incorporação de sólidos como conseqüência das trocas difusionais que ocorrem durante o processo, devido aos gradientes de concentração. Sankat et al. (1992) e Sousa (2002) observaram durante a desidratação osmótica de banana à pressão atmosférica, em soluções de sacarose de diferentes concentrações, que a perda de água e o ganho de sólidos aumentaram de acordo com a concentração inicial de sacarose na solução osmótica.

Observa-se ainda, nas mesmas figuras, que os tratamentos em que se utilizaram xaropes de sacarose a $55^{\circ}$ e a $65^{\circ}$ Brix alcançaram valor de perda de água de aproximadamente 45 e $50 \%$, respectivamente. Segundo Torreggiani (1993), deve-se favorecer a perda de água com o mínimo possível de ganho de sólidos, visto que este pode alterar o perfil nutricional e sensorial do produto. Com base nesse critério, selecionou-se para posterior avaliação da secagem em estufa, o tratamento no qual se utilizou xarope a $55^{\circ}$ Brix, visto ter sido o que apresentou menor taxa de incorporação de sólidos dentre os dois tratamentos em questão. $\mathrm{O}$ tempo estabelecido para o processo foi de 4 horas, visto que a maior taxa de transferência de massa se deu nesse período.

$\mathrm{Na}$ Figura 3, nota-se que o aumento na concentração do xarope ocasionou maior perda de peso do produto. A predominância da perda de água sobre o ganho de sólidos durante todo o processo osmótico explica a razão do balanço de massa negativo em todos os experimentos, registrado pela perda de peso. Observações semelhantes também foram feitas por Beristain et al. (1990), Lima et al. (2004) e Sousa (2002) durante a desidratação osmótica à pressão atmosférica de abacaxi, banana e melão, respectivamente. Segundo Beristain et al. (1990), este fato ocorreu devido à dificuldade de difusão da sacarose através da parede celular em virtude do seu elevado peso molecular, ao contrário das moléculas de água, que tem sua difusão favorecida.

Nas Figuras 4 a 6 encontram-se os parâmetros de perda de água, ganho de sólidos e perda de peso, respectivamente, em função do tempo, durante os experimentos para avaliação da desidratação osmótica de manga sob vácuo. 


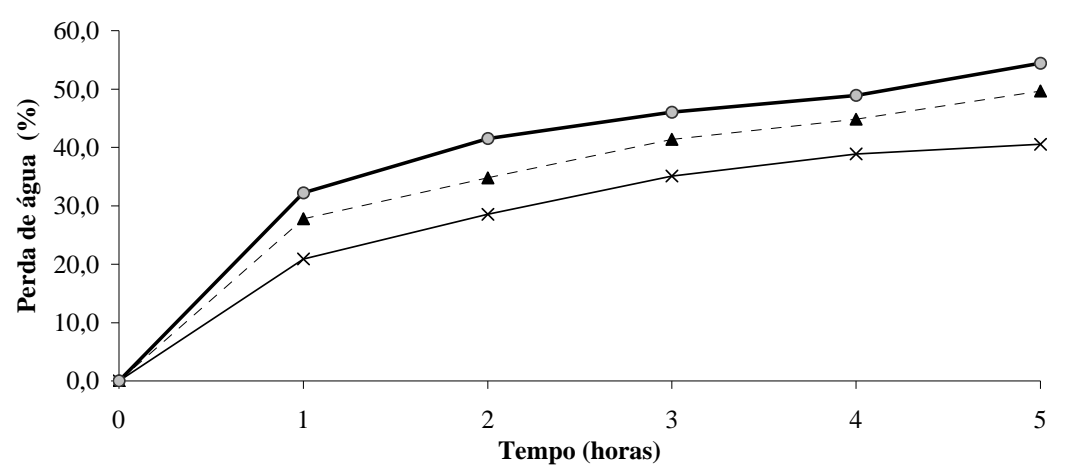

FIGURA 1 - Perda de água durante a desidratação osmótica de manga à pressão atmosférica, em xarope de sacarose nas concentrações de $45^{\circ}(\times), 55^{\circ}(\mathbf{\Lambda})$ e $65^{\circ}\left(^{\circ}\right)$ Brix.

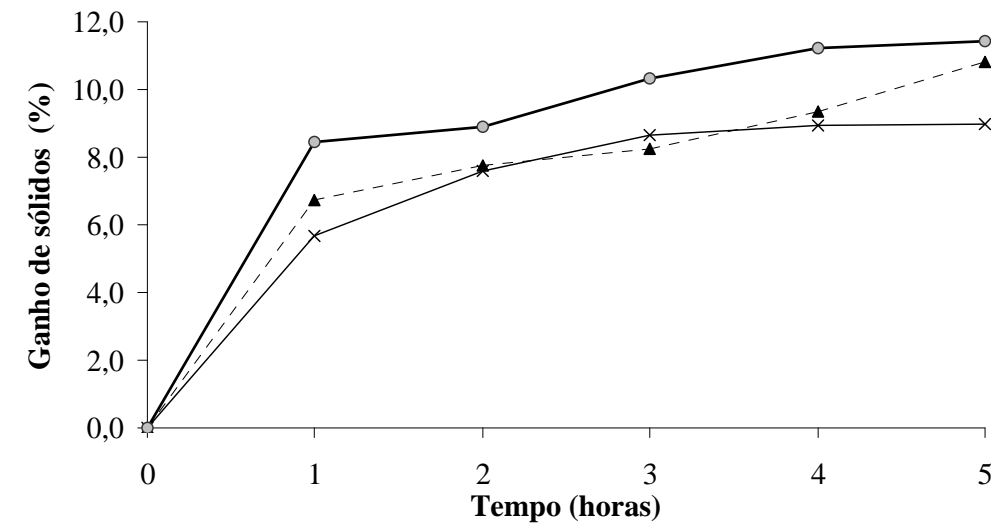

FIGURA 2 - Ganho de sólidos durante a desidratação osmótica de manga à pressão atmosférica, em xarope de sacarose nas concentrações de $45^{\circ}(\times), 55^{\circ}(\mathbf{\Delta})$ e $65^{\circ}\left(^{\circ}\right)$ Brix.

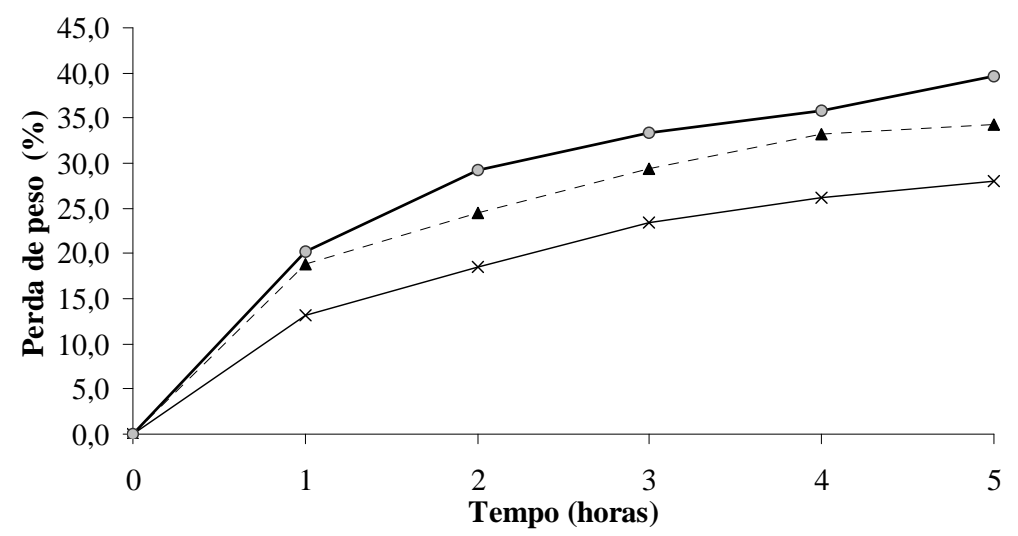

FIGURA 3 - Perda de peso durante a desidratação osmótica de manga à pressão atmosférica, em xarope de sacarose nas concentrações de $45^{\circ}(\times), 55^{\circ}(\mathbf{\Delta})$ e $65^{\circ}\left({ }^{\circ}\right)$ Brix.

Ciênc. agrotec., Lavras, v. 29, n. 5, p. 1021-1028, set./out., 2005 


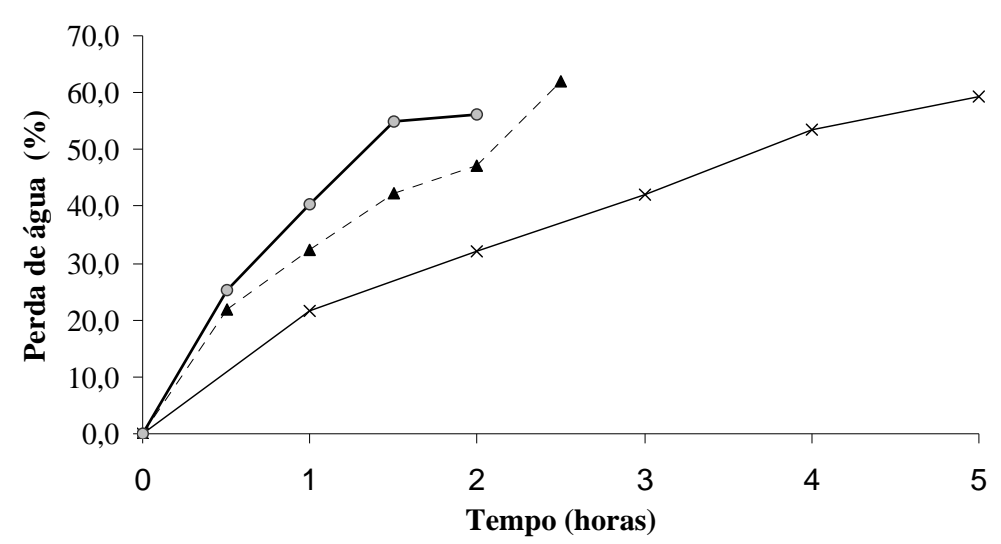

FIGURA 4 - Perda de água durante a desidratação osmótica de manga sob vácuo, em xarope de sacarose nas concentrações de $45^{\circ}(\times), 55^{\circ}(\mathbf{\Delta})$ e $65^{\circ}\left(^{\circ}\right)$ Brix.

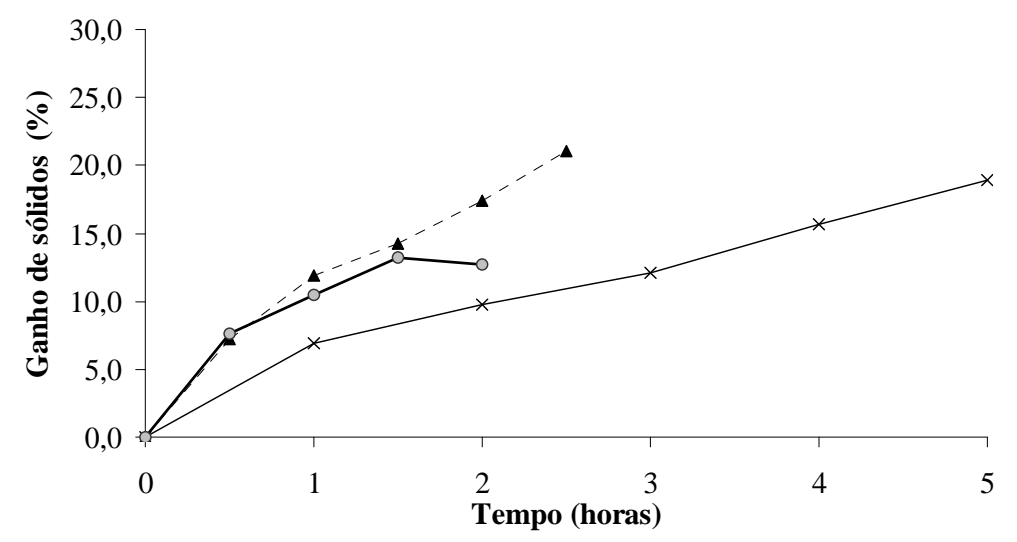

FIGURA 5 - Ganho de sólidos durante a desidratação osmótica de manga sob vácuo, em xarope de sacarose nas concentrações de $45^{\circ}(\times), 55^{\circ}(\mathbf{\Lambda})$ e $65^{\circ}\left(^{\circ}\right)$ Brix.

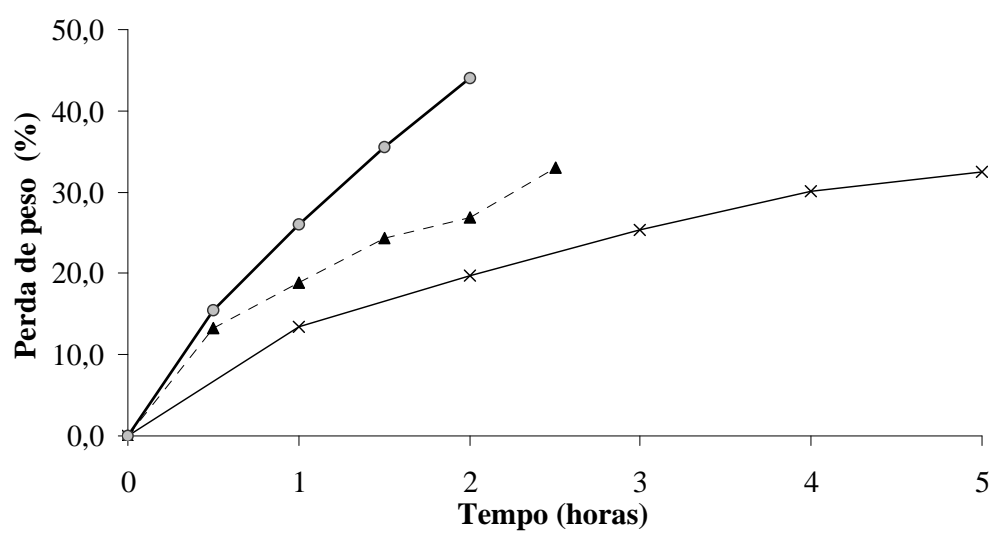

FIGURA 6 - Perda de peso durante a desidratação osmótica de manga sob vácuo, em xarope de sacarose nas concentrações de $45^{\circ}(\times), 55^{\circ}(\mathbf{\Lambda})$ e $65^{\circ}\left(^{\circ}\right)$ Brix. 
Durante a desidratação osmótica a vácuo, apenas o tratamento em que se utilizou xarope osmótico a $45^{\circ}$ Brix foi avaliado por um período de 5 horas. A utilização de vácuo, na temperatura de $65^{\circ} \mathrm{C}$, promoveu a concentração dos xaropes a 55 e $65^{\circ}$ Brix, devido à evaporação de parte da água da solução osmótica no decorrer do processo, com conseqüente cristalização do açúcar contido no xarope, impossibilitando a continuação da desidratação até o período preestabelecido.

Observa-se, nas Figuras 4 e 5, que a utilização de vácuo na desidratação osmótica da manga proporcionou a intensificação dos fluxos de transporte de massa no sistema quando comparados aos da desidratação sob pressão atmosférica (Figuras 1 e 2). Segundo Chiralt \& Fito (1996), a utilização do vácuo permite o aumento da interface sólido/ líquido devido à ocupação dos poros da matriz sólida (fruto) pela solução, o que explicaria maior remoção de água do fruto e maior ganho de sólidos durante a osmose demonstrados pelos tratamentos realizados sob vácuo.

Verifica-se que o tratamento osmótico sob vácuo em que se utilizou xarope de sacarose a $65^{\circ}$ Brix (Figura 4) apresentou, em apenas 2 horas de osmose, taxa de perda de água similar à obtida no processo osmótico sob pressão atmosférica, nas mesmas condições de concentração de xarope (Figura 1). Lima et al. (2004) observaram durante a desidratação osmótica de melão, em soluções de sacarose de diferentes concentrações $\left(45^{\circ}, 55^{\circ}\right.$ e $65^{\circ}$ Brix $)$, que a associação do vácuo com o aumento da concentração do xarope provocou também aceleração nas taxas de perda de água, tendo sido necessário menos tempo para que o tratamento osmótico (xarope a $65^{\circ} \mathrm{Brix}$ ) alcançasse uma perda de água similar à obtida no tratamento sob pressão atmosférica, nas mesmas condições de processo. Segundo Shi et al. (1995), a utilização de vácuo durante a desidratação osmótica contribui para acelerar a perda de água em comparação com o tratamento à pressão atmosférica, tornando o processo mais rápido e possibilitando a obtenção de frutos desidratados de boa qualidade.

Na desidratação osmótica a vácuo, a perda de água foi maior do que o ganho de sólidos, o que levou a uma perda de peso do produto (Figura 6). Resultados semelhantes foram vistos por Shi \& Fito (1993) e Sousa (2002) na desidratação osmótica a vácuo de abacaxi e banana.

Para avaliação da secagem em estufa, selecionouse o tratamento em que utilizou xarope de sacarose a $65^{\circ}$ Brix, visto ter sido o que alcançou, em apenas 2 horas de processo, alto grau de desidratação com ganho de sólidos relativamente pequeno, quando comparado aos demais tratamentos sob vácuo (Figuras 4 e 5).
Na Figura 7 são apresentadas a evolução da atividade de água e do teor de umidade da manga prétratada osmoticamente sob pressão atmosférica e a vácuo até o término da secagem.

O final de secagem foi estabelecido como o instante em que os frutos alcançaram níveis de atividade de água inferiores a 0,75. Assim, os tempos de secagem em estufa dos frutos pré-tratados osmoticamente à pressão atmosférica e a vácuo diferiram entre si, tendo sido de 16 e 14 horas, respectivamente (Figura 7).

A cinética de secagem da manga pré-tratada sob pressão atmosférica, mais lenta em relação à pré-tratada osmoticamente a vácuo, pode ser devida à formação de camada de soluto na superfície dos pedaços da fruta durante a desidratação osmótica à pressão atmosférica, a qual, segundo Borges \& Menegalli (1994) e Sankat et al. (1992), espessa-se com o tempo, aumentando a resistência ao movimento da água, retardando, assim, o processo de secagem.

Verifica-se pela Figura 7 que, para ambos os tratamentos, os valores de umidade e atividade de água após a secagem final encontraram-se dentro das faixas estabelecidas para alimentos com umidade intermediária os quais, segundo Aguilera \& Parada (1992), devem apresentar umidade variando de $15 \%$ a $40 \%$ e atividade de água entre 0,65 e 0,85 .

Pela Tabela 1 verificam-se as características do fruto desde o início do processo (fruto in natura), assim como após os diferentes tratamentos osmóticos e ao término da secagem.

De acordo com a Tabela 1, ao final da osmose, observa-se uma diferença nos valores de sólidos solúveis totais entre os dois tratamentos, tanto sob pressão atmosférica $\left(T_{1}\right)$, quanto sob vácuo $\left(T_{2}\right)$, o que pode ser justificado pela maior incorporação de sólidos durante $o$ processo osmótico sob vácuo. Ao final da secagem, verifica-se um aumento no teor de sólidos solúveis totais, devido à remoção de água no decorrer do processo ter provocado a concentração dos sólidos solúveis nos produtos. Observa-se ainda que os tratamentos osmóticos proporcionaram considerável redução nos níveis de umidade e atividade de água. Entretanto, produtos com essas características não são estáveis em prateleira, confirmando a necessidade de processamento complementar, conferindo-lhes características que os tornem estáveis sem necessidade de refrigeração, o que pode ser verificado nos valores de umidade e atividade de água dos produtos após a secagem em estufa, enquadrando-se como alimentos de umidade intermediária.

Ciênc. agrotec., Lavras, v. 29, n. 5, p. 1021-1028, set./out., 2005 

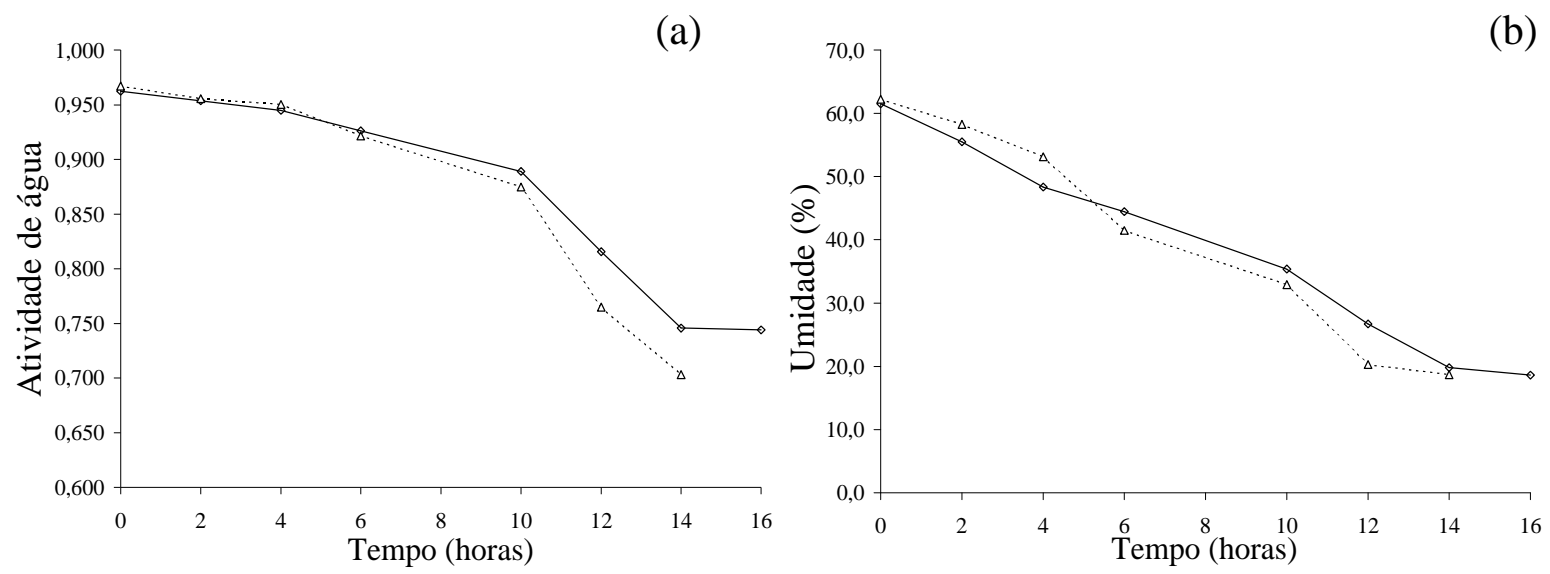

FIGURA 7 - Atividade de água (a) e teor de umidade (b) da manga após tratamento osmótico sob pressão atmosférica (一) e vácuo (…), em função do tempo de secagem.

TABELA 1 - Características físico-químicas durante o processo de desidratação osmótica da manga seguido de secagem em estufa.

\begin{tabular}{lccccc}
\hline \multicolumn{1}{c}{ Determinação } & Fruto in natura & \multicolumn{2}{c}{ Final da Osmose } & \multicolumn{2}{c}{ Final da Secagem } \\
\hline & & $\mathrm{T}_{1}$ & $\mathrm{~T}_{2}$ & $\mathrm{~T}_{1}$ & $\mathrm{~T}_{2}$ \\
\cline { 3 - 5 } & & 61,52 & 62,21 & 18,63 & 18,69 \\
Umidade (\%) & 86,61 & 0,962 & 0,967 & 0,744 & 0,703 \\
Atividade de Água (Aa) & 0,984 & 33,70 & 34,80 & 75,00 & 80,30 \\
Sólidos Solúveis ( ${ }^{\circ}$ Brix) & 12,50 &
\end{tabular}

$\mathrm{T}_{1}$ : Tratamento osmótico sob pressão atmosférica (xarope a $55^{\circ} \mathrm{Brix}$, por 4 horas) e secagem em estufa (por 16 horas); $\mathrm{T}_{2}$ : tratamento osmótico sob vácuo (xarope a $65^{\circ} \mathrm{Brix}$, por 2 horas) e secagem em estufa ( 14 horas).

\section{CONCLUSÕES}

O transporte de massa durante o pré-tratamento osmótico e a secagem complementar em estufa da manga são influenciados pela concentração da solução osmótica e pela pressão do sistema utilizadas.

As características do produto final são influenciadas pelas condições de processo, uma vez que a utilização de vácuo durante o processo contribuiu para acelerar a remoção de água do alimento, possibilitando a redução do tempo total de processamento.

A combinação do pré-tratamento osmótico com a secagem em estufa mostrou-se adequada para a obtenção de manga desidratada como produto de umidade intermediária e, portanto, com características de estabilidade que possibilitariam o seu armazenamento em temperatura ambiente.

\section{AGRADECIMENTOS}

Os autores agradecem à Embrapa Agroindústria Tropical e ao Banco do Nordeste pelo suporte financeiro.

\section{REFERÊNCIAS BIBLIOGRÁFICAS}

AGUILERA, J. M.; PARADA, E. CYTED-D AHI: IberoAmerican project on intermediate moisture foods and combined methods technology. Food Research International, Oxford, v. 25, n. 1, p. 159-165, 1992.

ASSOCIATION OF OFFICIAL ANALYTICAL CHEMISTS. Official methods of analysis of the Association of Official Analytical Chemists. 12. ed. Washington, 1992. $1115 \mathrm{p}$. 
BERISTAIN, C. I.; AZUARA, E.; CORTÉS, R.; GARCIA, H. S. Mass transfer during osmotic dehydration of pineapple rings. Food Science and Technology International, London, v. 25, n. 5, p. 576-582, 1990.

BORGES, S. V.; MENEGALLI, F. C. Influência da desidratação osmótica sobre a cinética de secagem de manga. Pesquisa Agropecuária Brasileira, Brasília, v. 29, n. 4, p. 637-642, 1994.

BRANDÃO, M. C. C.; MAIA, G. A.; LIMA, D. P.; PARENTE, E. J. S.; CAMPELLO, C. C.; NASSU, R. T.; FEITOSA, T.; SOUSA, P. H. M. Análise físico-química, microbiológica e sensorial de frutos de manga submetidos à desidratação osmótico-solar. Revista Brasileira de Fruticultura, Jaboticabal, v. 25, n. 1, p. 38-41, 2003.

CHIRALT, A.; FITO, P. Salting of manchego-type cheese by vacuum impregnation. In: FITO, P.; ORTEGA-RODRIGUEZ, E.; BARBOSA-CANOVAS, G. V. (Eds.). Food engineering 2000. New York: Chapman \& Hall, 1996. p. 215-230.

DEL VALLE, J. M.; CUADROS, T. R. M.; AGUILERA, J. M. Glass transitions and shrinkage during drying and storage of osmosed apple pieces. Food Research International, Oxford, v. 31, n. 3, p. 191-204, 1998.

LIMA, A. S.; FIGUEIREDO, R. W.; MAIA, G. A.; RIBEIRO, J.; SOUZA NETO, M. A.; SOUZA, A. C. Estudo das variáveis de processo sobre a cinética de desidratação osmótica de melão. Ciência e Tecnologia de Alimentos, Campinas, v. 24, n. 2, p. 282-286, 2004.

LOPÉZ-MALO, A. Self stable high papaya minimally processed by combined methods. Food Research International, Oxford, v. 27, n. 4, p. 545-553, 1994.

MASTRANGELO, M. M.; ROJAS, A. M.; CASTRO, M. A.; GERSCHENSON, L. N.; ALZAMORA, S. M. Texture and structure of glucose-infused melon. Journal of the Science of Food and Agriculture, Chichester, v. 80, p. 769-776, 2000.

MIZRAHI, S.; EICHLER, S.; RAMON, O. Osmotic dehydration phenomena in gel systems. Journal of Food Engineering, Oxford, v. 49, n. 1, p. 87-96, 2001.
PANAGIOTOU, N. M.; KARATHANOS, V. T.; MAROULIS, Z. B. Effect of osmotic agent on osmotic dehydration of fruits. Drying Technology, New York, v. 17, n. 1, p. 175-189, 1999.

RATTI, C. Hot air and freeze-drying of high-value foods: review. Journal of Food Engineering, Oxford, v. 49, n. 2, p. 311-319, 2001.

RIBEIRO, M. S.; SABAA-SRUR, A. U. O. Saturação de manga var. rosa com açúcares. Ciência e Tecnologia de Alimentos, Campinas, v. 19, n. 1, p. 118-122, 1999.

SACCHETTI, G.; GIANOTTI, A.; DALLA ROSA, M. Sucrose-salt combined effects on mass transfer kinetics and product acceptability. Journal of Food Engineering, Oxford, v. 49, n. 2, p. 163-173, 2001.

SANKAT, C. K.; CASTAIGNNE, F.; MAHARAJ, R. Banana dehydration: osmotic, air and solar effects. In: MUJUMDAR, A. S. Drying'92. Great Britain: Elsevier Science, 1992. p. 1679-1688.

SHI, X. Q.; FITO, P. Vacuum osmotic dehydration of fruits. Drying Technology, New York, v. 11, n. 6, p. 445-454, 1993.

SHI, X. Q.; FITO, P.; CHIRALT, A. Influence of vacuum treatment on mass transfer in osmotic dehydration of fruits. Food Research International, Oxford, v. 28, n. 5, p. 445454, 1995.

SOUSA, P. H. M. Desidratação osmótica de banana com e sem vácuo com complemento de secagem em estufa de circulação de ar. 2002. 90 f. Dissertação (Mestrado em Tecnologia de Alimentos) - Universidade Federal do Ceará, Fortaleza, 2002.

TORREGGIANI, D. Osmotic dehydration in fruit and vegetable processing. Food Research International, Oxford, v. 26, n. 1, p. 59-68, 1993.

TORREGGIANI, D.; BERTOLO, G. Osmotic treatments in fruit processing: chemical, physical and structural effects. Journal of Food Engineering, Oxford, v. 49, n. 2, p. 247256, 2001. 